\title{
A Criatividade Matemática nas Respostas de Alunos Participantes de uma Competição de Resolução de Problemas
}

\author{
Mathematical Creativity in the Solutions of Students Participating in a \\ Problem-Solving Competition
}

\author{
Nuno Amaral \\ Susana Carreira*
}

\begin{abstract}
Resumo
Assumindo a criatividade como um potencial que pode ser desenvolvido em todos os indivíduos, o objetivo deste estudo consiste em descrever, caracterizar e compreender a criatividade matemática manifestada nas respostas produzidas por alunos do Ensino Básico (10 a 12 anos) num campeonato de resolução de problemas de carácter inclusivo realizado através da Internet. A metodologia é de natureza interpretativa, utilizando a análise de conteúdo num conjunto de 10 resoluções a um dado problema. A análise apoia-se na aplicação de um referencial de criatividade matemática baseado nos parâmetros de originalidade, fluência e flexibilidade, adaptados à resolução de problemas matemáticos. Os resultados revelam diversas características da criatividade matemática nas produções dos participantes do campeonato, sobressaindo a primazia da originalidade que é reforçada pela capacidade de representação e de mobilização de conhecimento matemático. Apesar de ser variável a presença das três dimensões, o seu efeito combinado é determinante na individualização de resoluções matematicamente criativas.
\end{abstract}

Palavras-chave: Criatividade Matemática. Competições Matemáticas. Resolução de Problemas. Indicadores de Criatividade.

\begin{abstract}
Assuming creativity as a potential that can be developed in all individuals, the aim of this study is to describe, characterize, and understand mathematical creativity expressed in the solutions produced by elementary school students (10-12 years-old) in a problem-solving competition of an inclusive character and which runs through the Internet. The research method follows an interpretative approach, using content analysis in a set of 10 solutions to a given problem. The analysis draws on the application of a mathematical creativity framework based on the parameters of originality, fluency, and flexibility, which were adapted to mathematical problemsolving. The results reveal different features of mathematical creativity in the participants' productions in the competition, with originality standing out albeit reinforced by the ability to represent and retrieve mathematical knowledge. While the presence of the three dimensions is variable, their combined effect determines the unique character of mathematically-creative solutions.
\end{abstract}

Keywords: Mathematical Creativity. Mathematics Competitions. Problem-Solving. Creativity Indicators.

\footnotetext{
* Doutor em Educação, na especialidade de Didática da Matemática, pela Universidade de Lisboa, Lisboa, Portugal. Professor de Quadro de Escola no Agrupamento de Escolas Cardoso Lopes, Amadora, Portugal. Endereço para correspondência: Rua Chão da Armada, n. ${ }^{\circ}$ 17, Pinhão Douro, Portugal, CEP: 5085-038. E-mail: nualroam@gmail.com

** Doutora em Educação, na especialidade de Didática da Matemática, pela Universidade de Lisboa, Lisboa, Portugal. Professora Associada da Faculdade de Ciências e Tecnologia da Universidade do Algarve; Membro da Unidade de Investigação e Desenvolvimento em Educação e Formação (UIDEF), Instituto de Educação, Universidade de Lisboa, Portugal. Endereço para correspondência: Faculdade de Ciências e Tecnologia da Universidade do Algarve, Campus de Gambelas, Faro, Portugal, CEP: 8005-139. E-mail: scarrei@ualg.pt
} 


\section{Introdução}

Atualmente, muitos estudantes participam em atividades extracurriculares de aprendizagem da Matemática como forma de aumentar os seus conhecimentos e como oportunidade de alimentar o gosto por essa disciplina (KENDEROV et al., 2009). Esse tipo de atividades tem, sobretudo, como propósito atrair estudantes para o domínio da Matemática, dando-lhes liberdade para aprender de uma forma diferente, despertando a sua curiosidade e propondo-lhes desafios. Representam, por isso, um terreno rico em estímulos distintos daqueles que os alunos encontram habitualmente no contexto escolar (KENDEROV, 2006). Em todo o caso, o conhecimento e a experiência que os jovens têm possibilidade de adquirir nestes ambientes fora da sala de aula poderão contribuir positivamente para ampliar, diversificar e robustecer as suas aprendizagens escolares, sendo expectável que as diversas aprendizagens se complementem. Nesse sentido, e reconhecendo que a sala de aula é hoje apenas um dos contextos possíveis de aprendizagem, é importante ter-se em conta e conhecerse, tão profundamente quanto possível, o impacto e as potencialidades das competições relacionadas com a Educação e o saber matemático, nomeadamente as que acontecem para além do contexto escolar.

Procurando responder a esse interesse, foi desenvolvido em Portugal o projeto de investigação Problem@ Web $^{1}$ que se propôs estudar a resolução de problemas no contexto de competições matemáticas anuais baseadas na Internet (SUB12 e SUB14), segundo diversas linhas de investigação: o uso das tecnologias digitais, os aspectos afetivos e a criatividade matemática na resolução de problemas.

Com o presente artigo pretende-se relatar parte da investigação feita no âmbito desse projeto em torno da criatividade matemática na atividade de resolução de problemas, apresentando um recorte da tese de doutoramento, elaborada pelo primeiro autor (AMARAL, 2016), no contexto do SUB12 (alunos de 10 a 12 anos). O referido estudo assumiu como objetivo descrever, caracterizar e compreender a criatividade matemática manifestada nas resoluções construídas por alunos do Ensino Básico, durante a fase de apuramento do campeonato de resolução de problemas de matemática SUB12, ao longo de um período de três anos (edições 2010/11, 2011/12 e 2012/13).

\footnotetext{
${ }^{1}$ Projeto Problem@Web (Resolução de Problemas de Matemática: Perspectivas sobre uma competição interativa na web) financiado pela FCT - Fundação para a Ciência e Tecnologia, n. ${ }^{\circ}$ PTDC/CPE-CED/101635/2008 (execução: 2011-2014).
} 
Circunscrevendo a análise da criatividade matemática ao contexto do campeonato de resolução de problemas SUB12, a criatividade das resoluções submetidas pelos alunos participantes será aqui entendida em termos das dimensões cognitivas que são tipicamente atribuídas ao pensamento criativo, designadamente: originalidade, flexibilidade e fluência (SILVER, 1997; KARKOCKIENE, 2005). Partindo de uma perspectiva psicométrica, o presente trabalho de investigação visa propor e aplicar uma metodologia de análise da criatividade matemática das resoluções, procurando relacionar as três dimensões da criatividade com a atividade de resolução de problemas de crianças com aptidões matemáticas diversas e não necessariamente excepcionais.

Naturalmente, a criatividade matemática no contexto escolar é diferente da que poderá ser atribuída ao matemático profissional no seu campo de estudo. A distinção entre criatividade absoluta e criatividade relativa está baseada no modo como se estabelece aquilo que é novo (OREY, 2010). Ao nível da criatividade absoluta, denominada por vários autores de criatividade C-grande, o novo significará, por exemplo, um resultado matemático até então desconhecido e que adquire grande importância para a comunidade científica. Portanto, a criatividade absoluta está associada a descobertas que fazem avançar a Matemática como uma ciência, a nível global. Já no que diz respeito à criatividade relativa, por vezes designada de criatividade c-pequeno, um produto matemático criativo deverá ser, acima de tudo, algo de novo para a pessoa que o produziu ou para um determinado grupo de referência, como seria o caso de uma sala de aula (BEGHETTO; KAUFMAN, 2007, 2009; OREY, 2010). Assim, este estudo adere à perspectiva de que a criatividade deve ser considerada como relativa ao contexto em que se manifesta, isto é, será vista como uma criatividade inclusiva - a criatividade c-pequeno, em vez de C-grande - que nos impele a ver a diversidade e a singularidade na aparente banalidade das realizações do quotidiano.

\section{0 conceito de criatividade}

A noção de criatividade revela-se muito complexa, uma vez que varia de domínio para domínio, de uma sociedade para outra, estando longe de ser consensual o que se entende por produtos criativos, mesmo entre os especialistas. A literatura é rica em definições de criatividade, focando-se sobre o produto, o sujeito, a personalidade, a habilidade intelectual, os estilos de pensamento, o domínio do conhecimento, a motivação e os contextos onde o fenômeno ocorre (KARKOCKIENE, 2005; STARKO, 2010). Quando se busca a sua explicitação, percebe-se a dificuldade do conceito e o seu carácter multifacetado, que está 
longe de se resumir à questão da excepcionalidade ou a qualquer outro traço que se possa definir com precisão (SHARMA; TEPER, 2008). Na verdade, não há um conceito exato de criatividade, unânime ou sequer globalmente aceito em trabalhos de investigação; ao invés, são várias as definições encontradas na literatura que apresentam vários pontos comuns e que, ao mesmo tempo, enfatizam diferentes aspectos relacionados com o fenômeno. Por exemplo, é geralmente sublinhada a relação da criatividade com a capacidade de inovação (KARKOCKIENE, 2005). Contudo, sem rejeitarem a sua importância, diversos autores, como Beghetto (2013), argumentam que a inovação não é em si mesma suficiente para que algo seja considerado como um produto criativo; exige-se concomitantemente que tenha significado, relevância e utilidade, pretende-se que mostre adequação e eficácia. Para além da novidade ou originalidade, parece também haver concordância acerca das condições para a obtenção de resultados criativos, que incluem o conhecimento, as habilidades intelectuais, a motivação, o ambiente e o domínio de ideias específicas de uma dada área (SRIRAMAN, 2008).

Mas a natureza indeterminada do conceito de criatividade não pode tornar-se num rápido motivo para descartar a sua relevância pedagógica; o desenvolvimento da criatividade em todos os indivíduos deve ser um objetivo da educação escolar, independentemente da definição de criatividade adotada (LEIKIN; BERMAN; KOICHU, 2009). As perspectivas que dão ênfase ao desenvolvimento da criatividade preocupam-se igualmente com a construção de ferramentas que permitam a sua avaliação e evidenciar o seu desenvolvimento (LEIKIN, 2009). Entre outras, as noções de originalidade, fluência e flexibilidade, têm sido frequentemente usadas para construir ferramentas que ajudem a identificar evidências de criatividade nos alunos (MANN, 2006; SILVER, 1997). A avaliação de produtos criativos tem o seu paralelo nas pesquisas desenvolvidas pelo psicólogo norte-americano Guildford (1897-1987), focadas na avaliação do pensamento divergente, nas quais foram identificadas componentes que rapidamente foram transportadas para a avaliação da criatividade (CLARY; BRZUSZEK; FULFORD, 2011). Em particular, de entre as categorias identificadas por Guilford (1950), a flexibilidade, a fluência e a originalidade têm vindo a ser adotadas em diversos estudos que envolvem a construção de ferramentas para avaliar o desempenho e potencial criativo dos alunos (MANN, 2005; LEIKIN, 2009). No presente estudo, estas dimensões foram igualmente consideradas como convenientes para servir de base à descrição da criatividade matemática na resolução de problemas.

\subsection{Criatividade matemática na resolução de problemas}


Todos os indivíduos são, até certo ponto, criativos, embora evidentemente alguns o sejam mais do que outros. Parece, contudo, inegável que é preciso ter conhecimento suficiente sobre um determinado campo para o fazer avançar, pois dificilmente alguém conseguirá ir muito longe em qualquer área se não tiver conhecimentos sólidos sobre a mesma. Particularmente, no campo da resolução de problemas matemáticos a relativa proficiência depende do domínio de conhecimento por parte do solucionador (MAYER, 2006). Na verdade, o conhecimento prévio e as experiências anteriores são tudo o que um solucionador tem para desenhar uma estratégia para atacar um problema.

No âmbito do ensino e aprendizagem da Matemática, a fluência do conhecimento, vista como parte da proficiência matemática em resolução de problemas, é uma condição necessária para que qualquer aluno resolva problemas com sucesso e consiste na capacidade de aplicar estratégias e procedimentos com eficiência, precisão e flexibilidade (NCTM, 2014). A eficiência implica que um aluno não se enrede em muitas etapas ou não perca o controle da estratégia seguida, sendo capaz de recorrer a resultados intermédios para resolver os problemas; a precisão depende de vários aspectos do processo de resolução de problemas, entre eles, o registo cuidadoso, a aplicação de combinações numéricas e outras relações importantes, bem como a preocupação com os métodos de verificação e validação dos resultados; e, por último, a flexibilidade pressupõe o conhecimento de mais do que uma abordagem para resolver problemas, o que possibilita a escolha de uma estratégia adequada e, ao mesmo tempo, o uso de um método eficaz de verificação dos resultados (RUSSEL, 2000). Portanto, a fluência do conhecimento matemático significa mais do que a memorização de fatos ou procedimentos e é mais do que conhecer e ser capaz de usar um determinado procedimento matemático (NCTM, 2014; RUSSEL, 2000), pois assenta numa base de conhecimento matemático bem organizada.

A resolução de problemas é considerada, há décadas, como um importante veículo para a aprendizagem matemática, entre outros motivos, pelo fato de colocar grande ênfase no desenvolvimento da comunicação e do raciocínio matemático, mediante o recurso a múltiplas representações externas (BOAVIDA et al., 2008). A flexibilidade de representação é uma característica do pensamento criativo que tem grande relevância na resolução de problemas matemáticos e está associada à capacidade de superar a rigidez de pensamento e de romper com modelos mentais pré-construídos. Por isso, a flexibilidade de representação é uma característica dos alunos que escolhem formas de representação adequadas, tendo em conta a resolução das tarefas que lhes são propostas (NISTAL; DOOREN; CLAREBOUT; ELEN; VERSCHAFFEL, 2009). A liberdade para usar múltiplas representações permite que os 
alunos aprendam a tirar partido das que serão mais eficazes, selecionando-as e explorando-as de acordo com o seu grau de experiência e de conhecimento (AINSWORTH, 1999). Os contextos que dão espaço aos alunos para manifestarem as suas habilidades representacionais permitem-lhes reconhecer e compreender os pontos fracos e fortes das suas próprias representações, o que tem um papel decisivo no desenvolvimento do seu estilo de pensamento matemático (BERTHOLD; RENKL, 2005). O pensamento criativo é próprio dos alunos que apresentam simultaneamente fluidez representacional e precisão matemática, especialmente em contextos de resolução de problemas, levando-os a representar o conteúdo matemático das suas soluções de forma original e significativa (AIZIKOVITSH-UDI, 2014).

\subsection{Competições de resolução de problemas para além da sala de aula}

O reconhecimento de que a maioria dos alunos tem capacidade para construir significados pessoais e originais para fatos e resultados bem conhecidos e estabelecidos é o primeiro passo para reconhecer o seu potencial criativo (RUNCO, 2003). São muitos os investigadores que corroboram esta posição e que, por isso, defendem que a criatividade deve ser incentivada desde muito cedo (STEINBERG, 2013). Mas a criatividade nem sempre é visível no contexto da sala de aula, principalmente quando as atividades habituais se resumem a exercícios rotineiros e treino de técnicas que valorizam principalmente a rapidez ou a precisão, negligenciando o pensamento criativo. De fato, a indução e o avanço do pensamento matemático não são possíveis se os alunos trabalharem apenas sobre tarefas rotineiras, baseadas na aplicação de algoritmos fornecidos pelo professor e segundo as suas orientações (FREIMAN, 2006).

É sabido que o fenômeno da criatividade matemática pode ter expressão em qualquer contexto matemático e não está confinado ao meio escolar (APPLEBAUM; SAUL, 2009). A nível mundial, são várias as organizações que desenvolvem atividades extracurriculares de enriquecimento matemático, para além da sala de aula, fomentando o desenvolvimento da capacidade de resolução de problemas, por exemplo através de competições e torneios de diferentes tipos. Estas competições têm em comum um conjunto de atributos que incentivam a criatividade, indo para além do currículo normal, através de oportunidades desafiantes de contato com uma Matemática diferente da Matemática Escolar (TAYLOR; GOURDEAU; KENDEROV, 2004). Disponibilizam tempo suficiente para a ideação criativa, incubação e produção, permitem aos estudantes encontrarem abordagens inesperadas e inovadoras e fomentam uma variedade de estilos de representação, com reflexos importantes na 
criatividade, nomeadamente ao nível da comunicação matemática (LASSIG, 2012; FREIMAN, 2009; TAYLOR; GOURDEAU; KENDEROV, 2004). São ainda marcantes pelos efeitos que têm sobre as atitudes dos alunos em relação à Matemática, além de contribuírem para a concepção de que a Matemática não se resume a definições, teoremas, fórmulas, provas, etc., mas também integra processos que incluem experimentar, raciocinar, conjeturar, refutar e justificar. Constituem, pois, modelos dinâmicos que desafiam as salas de aula tradicionais, permitindo que os alunos organizem e regulem a sua própria aprendizagem, que se empenhem de forma independente ou em equipes, que superem as suas dificuldades e se tornem conscientes dos seus próprios processos de raciocínio, estratégias e métodos (FREIMAN; LIRETTE-PITRE, 2008). Para muitos alunos, o objetivo principal de se envolverem nesse tipo de competições não é alcançar a vitória, pois só o fato de participarem e serem apurados representa um fator de grande motivação (TAYLOR; GOURDEAU; KENDEROV, 2004).

Em suma, as atividades extracurriculares que decorrem para além da sala de aula, de que é exemplo o campeonato de resolução de problemas SUB12, prestam um serviço importante à Educação Matemática e a um grande número de alunos com potencial talento matemático, constituindo um complemento natural ao trabalho realizado em sala de aula (KOICHU; ANDZANS, 2009). O papel das iniciativas extracurriculares que se dedicam à resolução de problemas, ao desenvolvimento de capacidades transversais e ao cultivo do interesse por questões matemáticas desafiantes ainda está por ser explorado profundamente. Todavia, um dos seus grandes potenciais está na contribuição que podem dar para o desenvolvimento da criatividade matemática.

\section{Metodologia}

O objetivo deste estudo não se traduz na procura de formas de medição da criatividade matemática dos participantes ou das suas produções; pretende-se, antes, dar corpo a uma visão qualitativa da presença da criatividade matemática em resoluções de problemas que, de algum modo, se diferenciam entre si (CANDEIAS, 2008; MORAIS; AZEVEDO, 2009). Neste sentido, o estudo enquadra-se num paradigma interpretativo de investigação, seguindo uma metodologia de estudo de caso, fortemente apoiada pela análise de conteúdo (OLIVEIRA; ENS; ANDRADE; MUSSIS, 2003), uma vez que se constituíram como dados os produtos enviados pelos participantes através da Internet durante a sua participação no campeonato. Os dados empíricos são de tipo documental (documentos digitais) e a fonte é o 
ambiente natural em que se produzem, isto é, resultam da participação dos jovens numa competição que decorre através da Internet.

\subsection{O campo empírico}

A competição matemática de resolução de problemas SUB12 surgiu em Portugal, no ano letivo 2005/2006, promovida pela Universidade do Algarve; é dirigida a alunos de $5^{\circ}$ e $6^{\circ}$ ano do Ensino Básico (idades entre 10 e 12 anos), decorrendo anualmente através da Internet, ao longo de seis meses, e culminando com uma final presencial.

Os problemas propostos quinzenalmente no website do campeonato apresentam situações a propósito das quais os alunos podem desenvolver e explorar conceitos de vários tópicos de matemática escolar, bem como conceber e aplicar estratégias, de acordo com as suas preferências, nível de conhecimento e sagacidade. Os alunos enviam as suas resoluções por email para a equipe responsável que informa cada concorrente sobre o estado das resoluções enviadas, possibilitando a cada participante corrigir, completar e reenviar a sua resposta, durante o período de submissão estabelecido. É essencial neste campeonato que os participantes apresentem e expliquem todo o seu processo de resolução, de uma forma tão clara e completa quanto possível.

Este ambiente de competição online dá aos participantes tempo e liberdade para pensar, condições fundamentais para o desenvolvimento da criatividade que muitas vezes escasseiam na sala de aula devido à necessidade de seguir e cumprir o currículo ou a outros constrangimentos do sistema escolar. Constitui-se assim como um espaço para o desenvolvimento da criatividade matemática e do pensamento independente, onde os estudantes podem revelar o seu talento, desde logo quando conseguem resolver problemas de forma inesperada e inovadora (TAYLOR; GOURDEAU; KENDEROV, 2004). Esta liberdade que os alunos têm de pensar matematicamente permite-lhes descobrirem formas interessantes de resolver problemas, muitas vezes manifestadas em soluções originais (CHING, 1997).

\section{Análise de resoluções de um problema proposto no SUB12}

Tendo em conta o contexto e o objetivo do estudo, o primeiro critério que norteou a escolha das resoluções a serem analisadas foi o de serem consideradas originais, isto é, a primeira seleção foi feita em função da sua singularidade (STARKO, 2010). Assim, decidiuse que a originalidade seria, desde logo, o pilar estruturante de toda a análise das resoluções. 
Dito de outro modo, partiu-se da originalidade como grande critério de filtragem das resoluções a analisar (um conjunto de 10 resoluções para cada um dos problemas considerados). Depois, nesse grupo limitado de resoluções, partiu-se para uma análise fina em torno das três dimensões contempladas no referencial de análise adotado: Originalidade, Fluência de Conhecimento Matemático e Flexibilidade Representacional.

Sendo o propósito deste artigo relatar uma parcela do estudo da criatividade matemática manifestada nas resoluções dos participantes no SUB12, optou-se por considerar um único conjunto de 10 resoluções, que se referem ao problema 10 da fase de apuramento, na edição 2012/2013. O pequeno número de resoluções consideradas foi intencional, dado que prevalece a intenção de ilustrar, num número reduzido de produções, a operacionalização do referencial de análise proposto, de forma a encontrar elementos diferenciadores segundo os parâmetros de originalidade (dentro de um grupo alvo), fluência (mobilização de conhecimento matemático para produzir resoluções de forma clara e eficaz) e flexibilidade (adequação e pertinência das representações usadas).

Para a designação das resoluções no processo de análise foi-lhes atribuído um código alfanumérico constituído por duas letras e dois números: S1A10, S2A10,.. S10A10. A letra S indica solução (resposta); o primeiro número (de 1 a 10) traduz a ordem de análise da solução no conjunto das 10 soluções; a letra A identifica a edição 2012/2013 do campeonato; o último número designa o problema em causa na referida edição (problema 10).

\subsection{O referencial de análise}

Ainda que o presente estudo se apoie no modelo psicométrico que está na base dos testes de criatividade e de pensamento divergente, designadamente ao assumir como componentes da criatividade matemática a originalidade, a fluência e a flexibilidade, pretende-se sobretudo caracterizar a criatividade dos produtos enviados pelos participantes para o Campeonato de Matemática SUB12. O intuito é propor uma ferramenta de análise para examinar, como uma lente amplificadora, algumas das soluções propostas pelos concorrentes que, de alguma forma, manifestam uma criatividade específica do contexto em que esta emerge, tendo em conta as capacidades, conhecimentos, perspicácia e ideias produtivas dos alunos a que este campeonato se destina.

O referencial, apresentado no Quadro 1, estabelece o conhecimento como um pano de fundo essencial, sendo preciso sublinhar que se trata do conhecimento matemático e da experiência de resolução de problemas matemáticos expectáveis em jovens com um grau de 
preparação matemática consonante com o seu nível escolar e enformada pelo currículo a que são expostos nas aulas de Matemática. Contudo, não são negligenciadas as capacidades e os conhecimentos informais, ou as formas de pensar e de comunicar próprias. A partir do conhecimento, surgem três indicadores de criatividade codificados: a originalidade $(O)$ reflete a capacidade de gerar resoluções próprias e singulares, dentro da amostra, tendo naturalmente em conta os contornos da competição e o nível de desenvolvimento que é alcançável pelos participantes; a fluência $(F n)$ implica a capacidade de usar conhecimento matemático de forma clara e eficaz para construir estratégias, encadear raciocínios e executar operações e procedimentos e comunicar as resoluções dos problemas, de forma clara, objetiva e precisa; e a flexibilidade $(F x)$, entendida como flexibilidade representacional, está associada à capacidade de selecionar, combinar, usar e adaptar representações, de acordo com as características dos problemas a resolver. Por sua vez, um conjunto de descritores são usados para caracterizar, de uma forma tão concreta e específica, quanto possível, o potencial criativo de cada resolução.

\begin{tabular}{|c|c|c|}
\hline $\begin{array}{l}\text { Domínio de } \\
\text { conhecimento }\end{array}$ & $\begin{array}{l}\text { Indicadores } \\
\text { (Código) }\end{array}$ & $\begin{array}{c}\text { Descritores } \\
\text { (Códigos) }\end{array}$ \\
\hline \multirow{3}{*}{$\begin{array}{l}\text { Resolução de } \\
\text { problemas } \\
\text { matemáticos }\end{array}$} & $\begin{array}{l}\text { Originalidade } \\
\text { (O) }\end{array}$ & $\begin{array}{l}\text { Novidade (N) } \\
\text { 1.Resolução eficaz e invulgar (N1) } \\
\text { 2.Recorre a ideias significativas e incomuns (N2) } \\
\text { 3.Estratégia adequada e singular (N3) } \\
\text { 4.Raciocínio claro e invulgar (N4) } \\
\text { 5.Comunicação objetiva e distinta (N5) }\end{array}$ \\
\hline & $\begin{array}{l}\text { Fluência/ } \\
\text { Proficiência } \\
\text { (Fn) }\end{array}$ & $\begin{array}{l}\text { Conhecimento matemático }(\mathrm{C}) \\
\text { 1. Conhecimento matemático mobilizado apropriadamente }(\mathrm{C} 1) \\
\text { 2. Conhecimento matemático em sintonia com os dados e condições do } \\
\text { problema (C2) } \\
\text { 3. Conhecimento matemático executado com perspicácia e eficiência (C3) } \\
\text { 4. Conhecimento matemático processual aplicado de forma simples e eficaz } \\
\text { (C4) } \\
\text { 5. Conhecimento matemático conceptual expresso através de métodos } \\
\text { próprios (C5) } \\
\text { 6. Conhecimento matemático reflete compreensão do problema (C6) } \\
\text { 7. Conhecimento matemático estruturado por etapas estrategicamente } \\
\text { organizadas (C7) }\end{array}$ \\
\hline & $\begin{array}{l}\text { Flexibilidade } \\
\text { (Fx) }\end{array}$ & $\begin{array}{l}\text { Representações (R) } \\
\text { 1. Utiliza representações adequadas (R1) } \\
\text { 2. Representações traduzem clara ligação do conhecimento matemático aos } \\
\text { dados (R2) } \\
\text { 3. Recorre a diferentes sistemas de representação eficazmente interligados } \\
\text { (R3) } \\
\text { 4. Constrói representações próprias pertinentes (R4) } \\
\text { 5. Recorre a representações estratégicas com eficácia (R5) } \\
\text { 6. Representações refletem o processo de raciocínio utilizado explicitamente } \\
\text { (R6) } \\
\text { 7. Representações permitem uma comunicação nítida e perspicaz (R7) }\end{array}$ \\
\hline
\end{tabular}

Quadro 1 - Referencial de análise da criatividade matemática

Fonte: Autores (2016) 
No contexto deste estudo, o conceito de criatividade é definido pela conjugação das componentes Originalidade, Fluência do Conhecimento Matemático e Flexibilidade Representacional num sistema integrado, sendo que a originalidade é o primeiro indicador para que uma resolução seja considerada criativa mas não é suficiente para descrever o produto criativo. Assim, a originalidade refere-se à singularidade das resoluções; a fluência consiste na mobilização do conhecimento matemático necessário e apropriado para resolver o problema; e a flexibilidade refere-se às formas de representação adequadas para exprimir o conhecimento envolvido e que intervêm na comunicação matemática da resolução.

\subsection{Operacionalização do referencial de análise}

O referencial de análise foi usado em primeiro lugar para detectar evidências da originalidade (cinco parâmetros) e, depois, de forma interligada, para identificar manifestações de fluência (sete parâmetros) e de flexibilidade (sete parâmetros).

O Quadro 2 exemplifica o meio utilizado para o registro e organização das evidências de criatividade retiradas da análise das resoluções da amostra selecionada, em termos dos dezenove descritores considerados no referencial de análise. Uma vez que a análise foi efetuada com base na comparação das resoluções, não só no seio da amostra como também no conjunto de todas as resoluções recebidas no campeonato para o mesmo problema, recorreuse aos símbolos + (mais), - (menos) e 0 (zero), para registar uma maior (+) ou uma menor (-) evidência dos descritores ou a sua total ausência (0) nas resoluções examinadas. Assim, cada linha do quadro exibe a codificação de cada uma das resoluções, de acordo com os indicadores utilizados.

\begin{tabular}{|c|c|c|c|c|c|c|c|c|c|c|c|c|c|c|c|c|c|c|c|}
\hline \multicolumn{20}{|c|}{ Problema ? - Edição ? (Fase Apuramento) } \\
\hline Indicadores & \multicolumn{5}{|c|}{ Originalidade $(O)$} & \multicolumn{7}{|c|}{ Fluência/Proficiência (Fn) } & \multicolumn{7}{|c|}{ Flexibilidade (Fx) } \\
\hline \multirow{2}{*}{ Descritores } & \multicolumn{5}{|c|}{ Novidade $(\mathbf{N})$} & \multicolumn{7}{|c|}{ Conhecimento Matemático (C) } & \multicolumn{7}{|c|}{ Representações (R) } \\
\hline & N1 & $\mathbf{N 2}$ & N3 & N4 & N5 & C1 & $\mathbf{C 2}$ & $\mathrm{C3}$ & $\mathrm{C4}$ & C5 & C6 & C7 & R1 & $\mathbf{R 2}$ & R3 & R4 & R5 & R6 & $\mathbf{R 7}$ \\
\hline S1 & + & + & - & $\mathbf{0}$ & - & & & & & & & & & & & & & & \\
\hline $\mathbf{S 2}$ & - & - & $\mathbf{0}$ & + & $\mathbf{0}$ & & & & & & & & & & & & & & \\
\hline S3 & & & & & & & & & & & & & & & & & & & \\
\hline $\mathbf{S 4}$ & & & & & & & & & & & & & & & & & & & \\
\hline S5 & & & & & & & & & & & & & & & & & & & \\
\hline S6 & & & & & & & & & & & & & & & & & & & \\
\hline S7 & & & & & & & & & & & & & & & & & & & \\
\hline S8 & & & & & & & & & & & & & & & & & & & \\
\hline S9 & & & & & & & & & & & & & & & & & & & \\
\hline S10 & & & & & & & & & & & & & & & & & & & \\
\hline
\end{tabular}

Quadro 2 - Registo de evidências dos descritores que compõem o referencial 
Fonte: Autores (2016)

A informação alusiva a cada resolução, além de registrada num quadro como o anterior, foi condensada em gráficos tridimensionais, cujo modelo é o paralelepípedo da Figura 1.

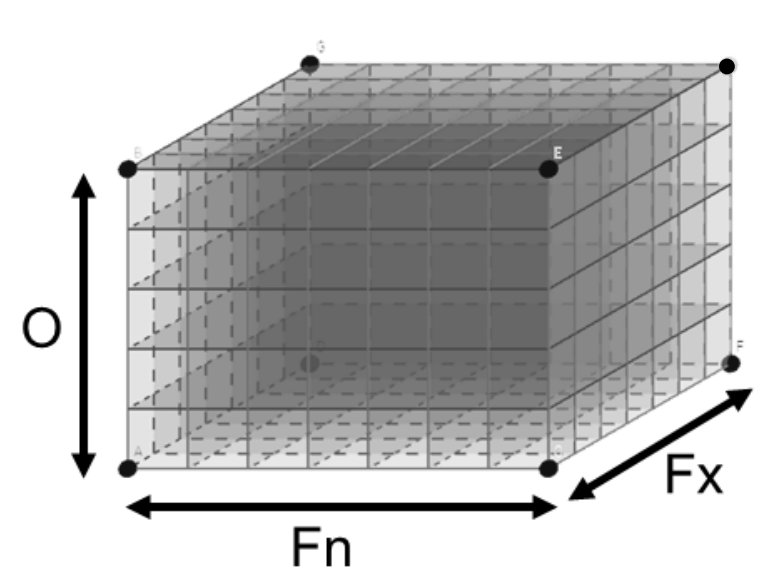

Figura 1 - Gráfico tridimensional ilustrativo das três dimensões do referencial Fonte: Autores (2016)

De acordo com o esquema tridimensional, a dimensão da originalidade é associada à altura; a dimensão da fluência do conhecimento matemático corresponde ao comprimento; e a dimensão da flexibilidade representacional está associada à largura.

Nos paralelepípedos, em qualquer das dimensões, é representado o somatório dos descritores sinalizados com + e -, sendo o sinal mais correspondente a 1 unidade e o sinal menos a $1 / 2$ unidade. Os descritores classificados com o valor 0 não contribuem para 0 resultado do respectivo somatório.

\subsection{Análise de resoluções do problema 10 da edição 2012/13}

Para resolver o problema "Pequeno-almoço no hotel" (Figura 2), lançado na fase de apuramento do SUB12 da edição 2012/2013, era essencial saber interpretar os dados do enunciado e a partir deles obter informação que não é dada imediatamente. Não era essencial ou determinante a aplicação de conteúdos curriculares específicos, além de que os participantes dispunham de toda a liberdade para usar métodos singulares de resolução e inclusive para inventar estratégias próprias, podendo, portanto, chegar ao resultado de várias formas possíveis. 


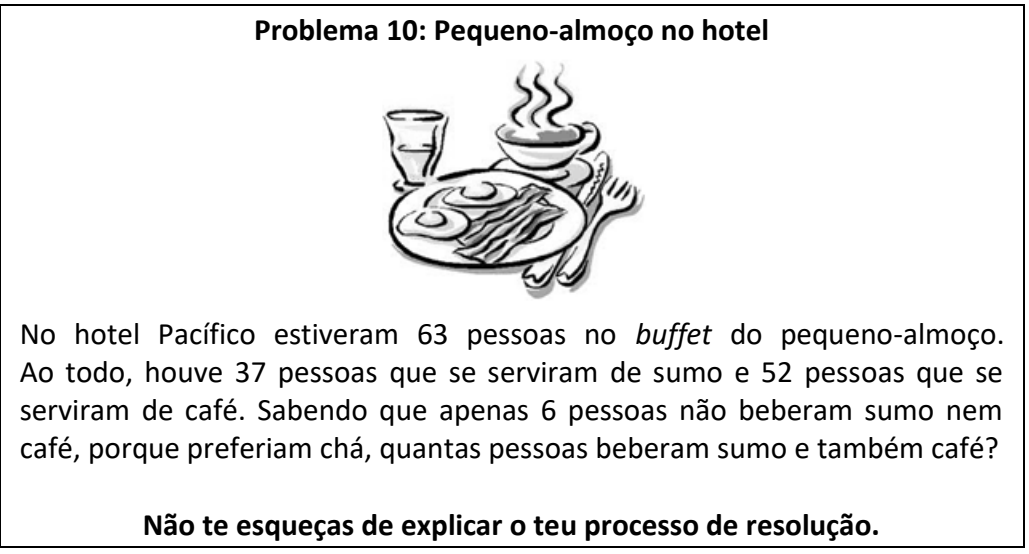

Figura 2 - Problema 10 do SUB12, edição 2012/2013

Fonte: Página Web do SUB12 (http://fctec.ualg.pt/matematica/5estrelas/subs/prob10_12.pdf)

Tendo em mente o referencial de análise estabelecido para descrever o fenômeno da criatividade no contexto deste estudo, após a seleção das 10 resoluções, procedeu-se ao seu agrupamento em função do tipo de representações mobilizadas em cada caso respectivamente, diagramas de Venn (Figuras 3, 4 e 5), tabelas (Figuras 6, 7 e 8), esquemas simbólicos (Figuras 9 e 10) e esquemas pictóricos (Figuras 11 e 12) - para exprimir o processo de resolução implementado.

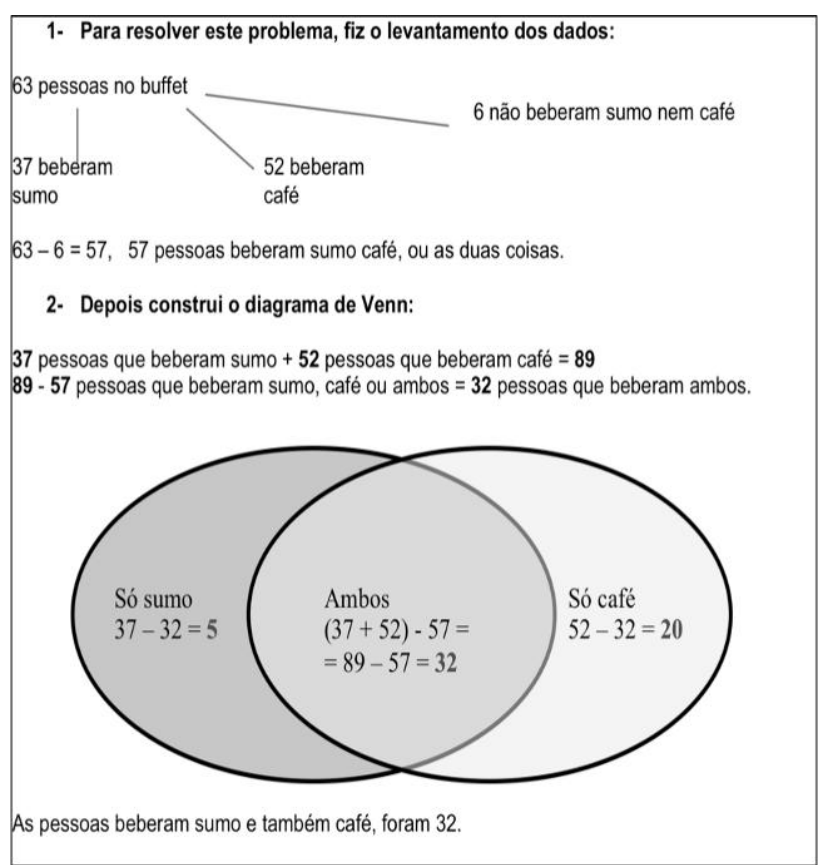

Figura 3 - Resolução S1A10 (diagrama de Venn) Fonte: Dados da pesquisa (2016)
Comecei por retirar às 63 pessoas que estiveram no buffet do pequeno almoço, as que só beberam chá, pois não me interessavam para a minha resposta e fiquei com 57 pessoas que beberam café e/ou sumo, dum total de 89 ( 37 sumo+52 café).

> A interseção destes dois números de pessoas 89 e 57 , vai-me dar as pessoas que beberam as duas bebidas. Então $89-57=32$.

> Confirmei, representando a situação num diagrama de Venn e já tinha utilizado na

> aula para resolver um problema parecido com este:

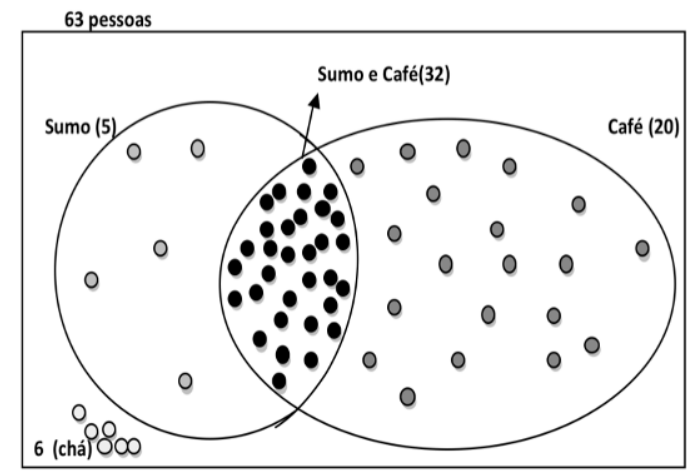

Depois confirmei com cálculos:

Café + Sumo + Chá + Café e sumo $=20+5+6+32=63$ pessoas

Figura 4 - Resolução S2A10 (diagrama de Venn) Fonte: Dados da pesquisa (2016) 


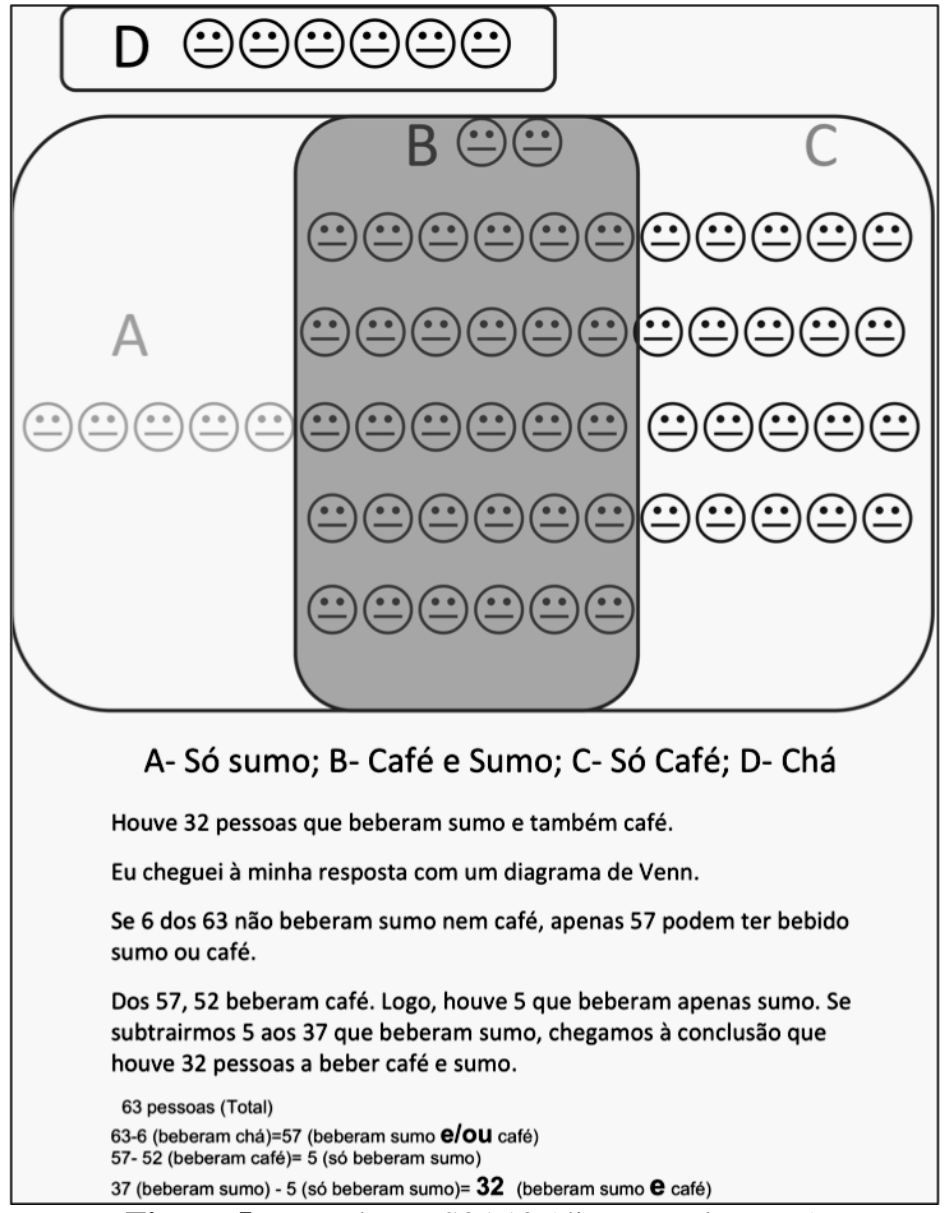

Figura 5 - Resolução S3A10 (diagrama de Venn) Fonte: Dados da pesquisa (2016)

No hotel Pacifico estiveram 63 pessoas no buffet do pequeno almoço.

Ao todo, houve 37 pessoas que se serviram de sumo e 52 pessoas que se serviram de café. Sabendo que apenas 6 pessoas não beberam sumo nem café porque preferiam chá, quantas pessoas beberam sumo e também café?

\section{RESOLUÇÃO:}

Para resolvermos este problema, elaborámos uma tabela que preenchemos com os dados que nos eram fornecidos no enunciado, Assim:

\begin{tabular}{|c|c|c|c|}
\hline & Sumo & Não Sumo & TOTAL \\
\hline Café & 32 & 20 & 52 \\
\hline Não Café & 5 & 6 & 11 \\
\hline TOTAL & 37 & 26 & 63 \\
\hline
\end{tabular}

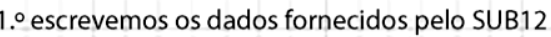

2. preenchemos um total e uma célula que nos forneceram o resto dos números

3. foi fazer as contas para preencher o resto

RESPOSTA: Vendo os dados na tabela, reparamos que o número de pessoas que bebeu café e sumo foi de 32 .

Figura 6 - Resolução S4A10 (tabela)

Fonte: Dados da pesquisa (2016) 


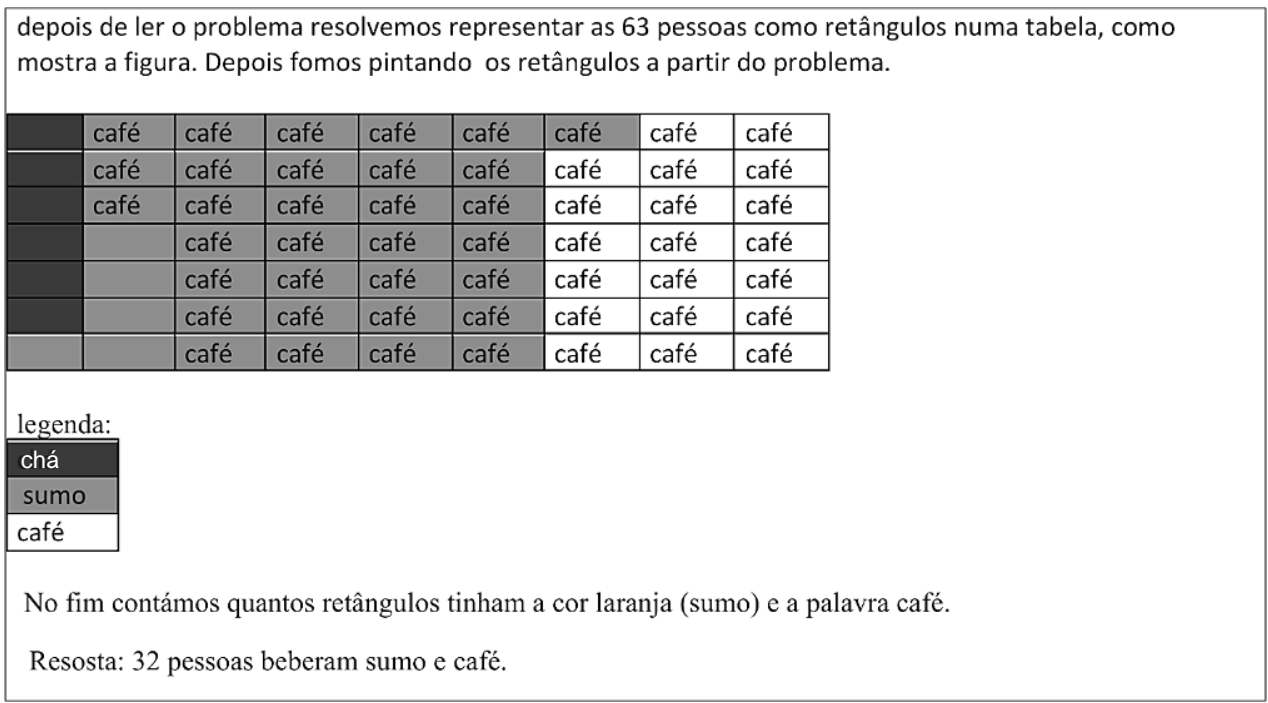

Figura 7 - Resolução S5A10 (tabela)

Fonte: Dados da pesquisa (2016)

\begin{tabular}{||l|c|c|c|}
\hline Bebida & Café & Sumo & Chá \\
\hline Número & 52 & 37 & 6 \\
\hline
\end{tabular}

63-6 = 57 Clientes hotel - consumidores de chá $=57$ pessoas

$52+37=89$ Consumidores de café + consumidores de sumo = 89 consumidores de café e /ou sumo

$89-57=\underline{32}$ Consumidores de café e $/$ ou sumo -57 pessoas $=\underline{32}$ pessoas de beberam café e sumo

Também poderia resolvê-lo assim:

63-6=57 Clientes hotel - consumidores de chá $=57$ pessoas

57-52 $=5$ Pessoas -52 consumidores de café $=5$ consumidores de só sumo

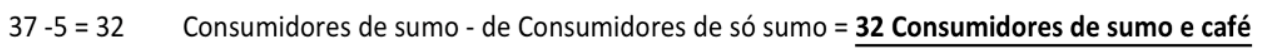

Figura 8 - Resolução S6A10 (tabela)

Fonte: Dados da pesquisa (2016) 


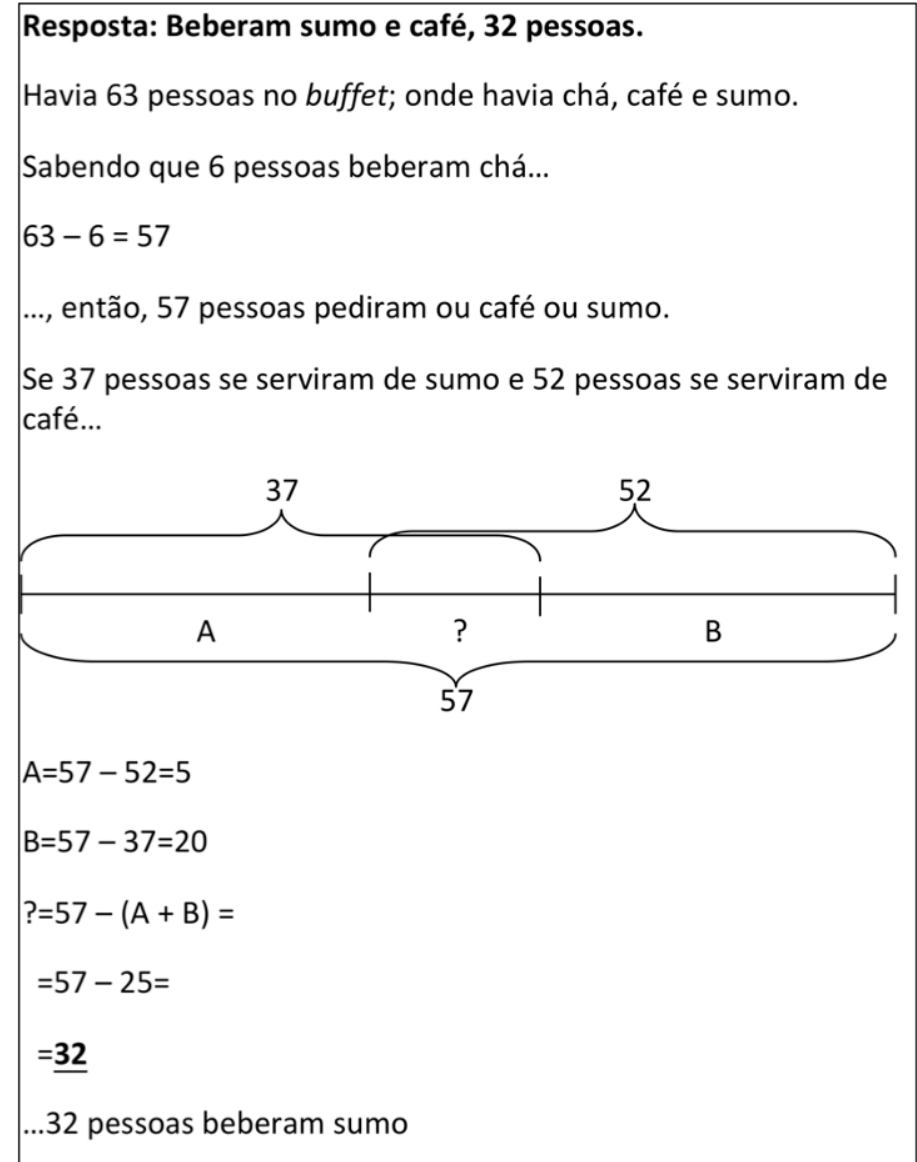

Figura 9 - Resolução S7A10 (esquema simbólico/algébrico) Fonte: Dados da pesquisa (2016)

No hotel Pacífico estiveram 63 pessoas no buffet do pequeno almoço. Ao todo, houve 37 pessoas que se serviram de sumo e 52 pessoas que se serviram de café. Sabendo que apenas 6 pessoas não beberam sumo nem café porque preferiam chá, quantas pessoas beberam sumo e também café?

Não te esqueças de explicar o teu processo de resolução.

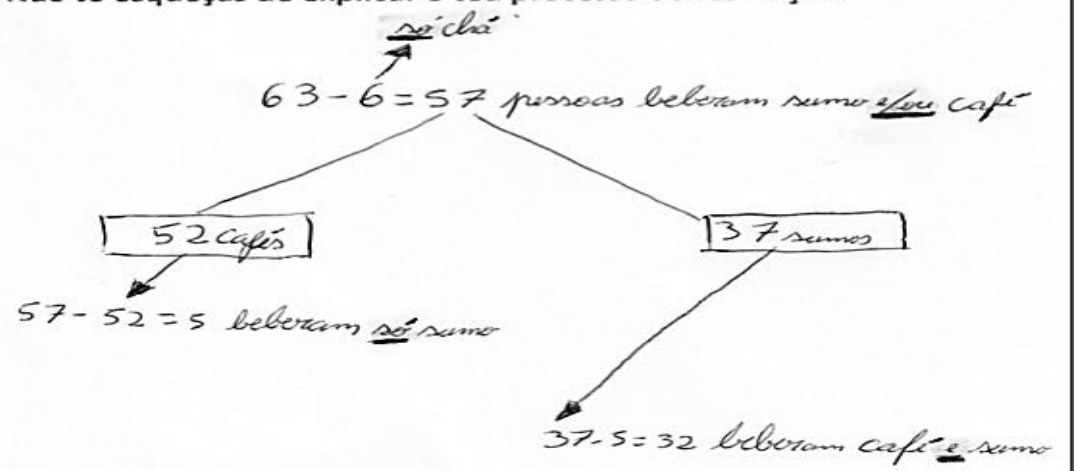

Figura 10 - Resolução S8A10 (esquema simbólico/algébrico)

Fonte: Dados da pesquisa (2016) 


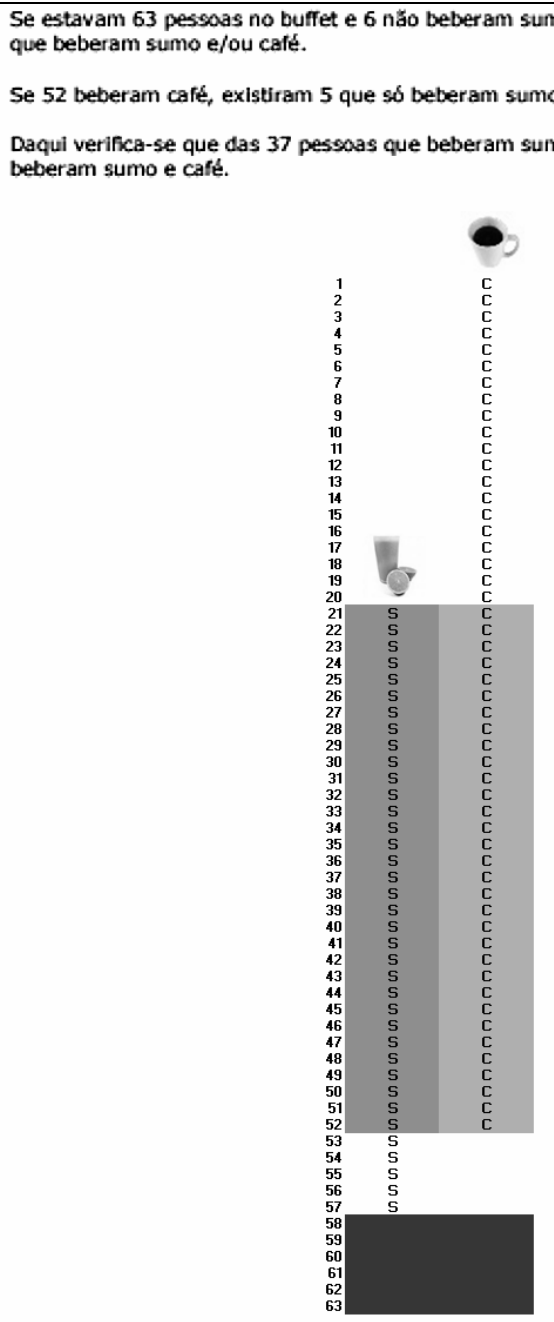

Resposta: 32 pessoas beberam sumo e caf6

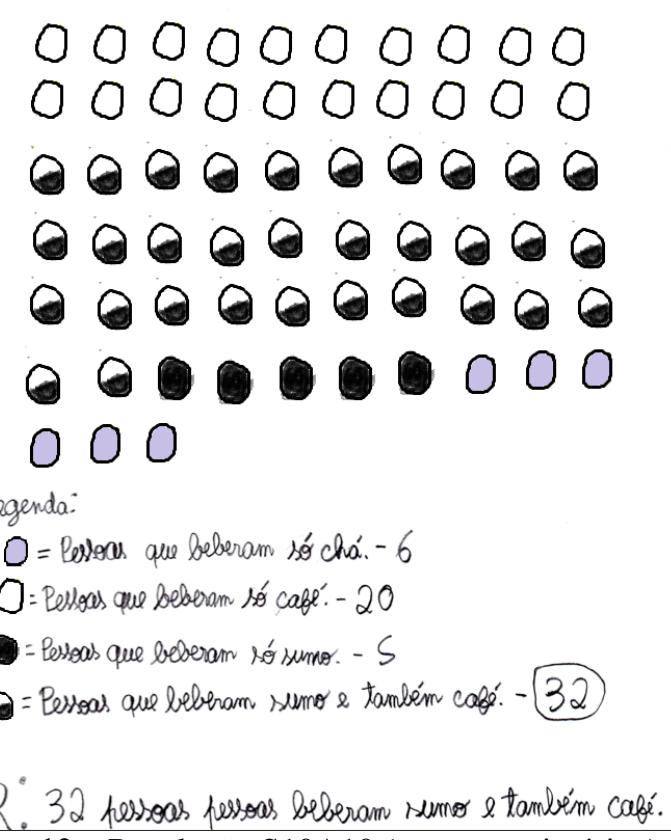

Figura 12 - Resolução S10A10 (esquema pictórico)

Fonte: Dados da pesquisa (2016)

No Quadro 3, apresentam-se os resultados da aplicação do referencial proposto.

\begin{tabular}{|c|c|c|c|c|c|c|c|c|c|c|c|c|c|c|c|c|c|c|c|}
\hline \multirow{3}{*}{ Descritores } & \multicolumn{5}{|c|}{ Originalidade $(\mathrm{O})$} & \multicolumn{7}{|c|}{ Fluência/Proficiência (Fn) } & \multicolumn{7}{|c|}{ Flexibilidade $(\mathbf{F x})$} \\
\hline & \multicolumn{5}{|c|}{ Novidade $(\mathrm{O})$} & \multicolumn{7}{|c|}{ Conhecimento Matemático (C) } & \multicolumn{7}{|c|}{ Representações (R) } \\
\hline & N1 & $\mathbf{N} 2$ & N3 & N4 & N5 & C1 & $\mathrm{C2}$ & C3 & $\mathrm{C4}$ & C5 & C6 & C7 & R1 & $\mathbf{R 2}$ & $\mathbf{R 3}$ & $\mathbf{R 4}$ & R5 & R6 & R7 \\
\hline S1A10 & + & - & + & - & + & + & + & + & + & $\mathbf{0}$ & + & + & + & + & + & $\mathbf{0}$ & + & + & + \\
\hline S2A10 & + & - & + & - & - & + & + & - & + & $\mathbf{0}$ & + & - & + & - & - & + & - & + & - \\
\hline S3A10 & + & - & + & - & + & + & + & + & + & $\mathbf{0}$ & + & - & + & + & + & + & + & + & + \\
\hline S4A10 & + & + & + & + & + & + & + & + & - & + & + & - & + & + & + & $\mathbf{0}$ & + & - & - \\
\hline S5A10 & + & - & - & - & + & + & + & - & - & + & + & - & + & + & + & $\mathbf{0}$ & + & - & - \\
\hline S6A10 & + & - & - & - & + & + & + & + & + & $\mathbf{0}$ & + & + & + & + & + & $\mathbf{0}$ & 0 & + & + \\
\hline S7A10 & + & + & + & + & + & + & + & + & + & + & + & + & + & + & + & + & + & + & + \\
\hline S8A10 & + & - & + & - & + & + & + & + & + & $\mathbf{0}$ & + & + & + & + & + & + & $\mathbf{0}$ & + & + \\
\hline S9A10 & + & + & + & + & - & + & + & - & - & + & + & + & + & + & + & + & + & + & + \\
\hline S10A10 & + & + & + & + & - & + & + & - & - & + & + & - & + & + & + & + & + & + & - \\
\hline
\end{tabular}

Quadro 3 - Evidências da criatividade nas resoluções S1 a S10

Fonte: Autores (2016) 
Adicionalmente, os dados apresentados no Quadro 3 foram traduzidos em gráficos tridimensionais (Figura 13) como forma de descrição sintética das resoluções analisadas. Pretende-se, com os dados codificados no Quadro 3 e com as representações gráficas da Figura 13, obter uma perspectiva geral da criatividade manifestada neste conjunto de 10 resoluções, no contexto do SUB12, na fase de apuramento considerada.

Em termos de originalidade, as resoluções são consideradas originais quando se distinguem ao serem comparadas com todas as demais que foram enviadas para a organização do SUB12 em resposta ao mesmo problema. Nos gráficos tridimensionais, a variação da altura está diretamente relacionada com a codificação de parâmetros que traduzem o invulgar, o singular, o incomum, o distinto, ou o diferente, ainda que sempre associados às noções de eficácia, de êxito, de validade, utilidade, etc., aparentes nas resoluções propostas.

No que diz respeito à fluência e à flexibilidade, a codificação das resoluções atendeu à mobilização e aplicação de conhecimento matemático (ideias, conceitos, procedimentos, raciocínios, estratégias de resolução) em articulação com a flexibilidade representacional (uso de representações adequadas e estrategicamente escolhidas, conexão entre sistemas de representação, capacidade expressiva, clareza, simplicidade, consistência). Estas duas dimensões traduzem-se por variações no comprimento e na largura, respectivamente, do paralelepípedo. 
S1A10

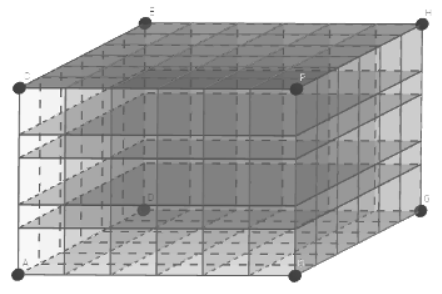

S4A10

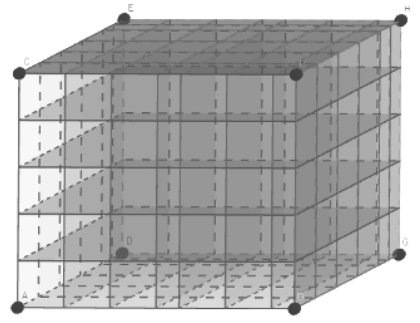

S7A10

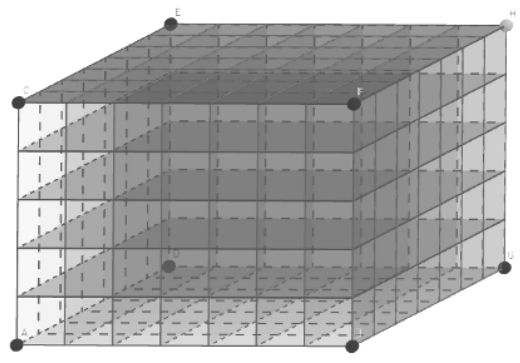

S9A10

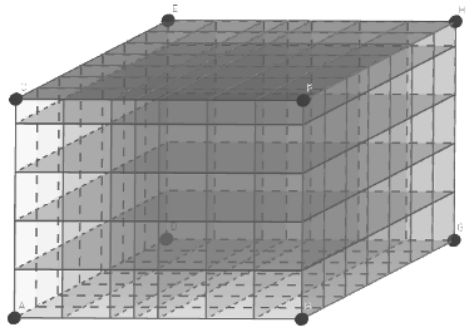

S2A10

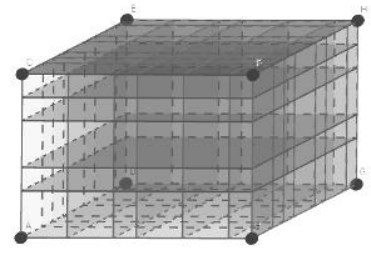

S5A10

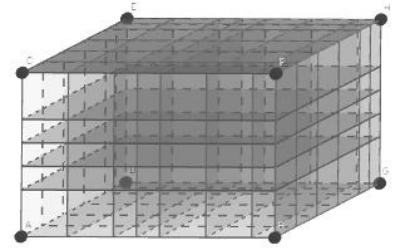

\section{S3A10}

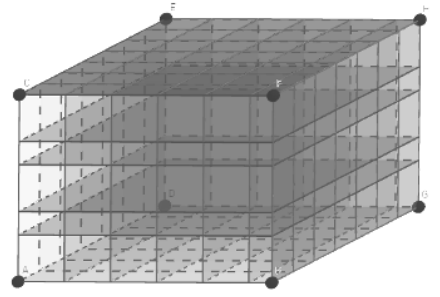

S6A10

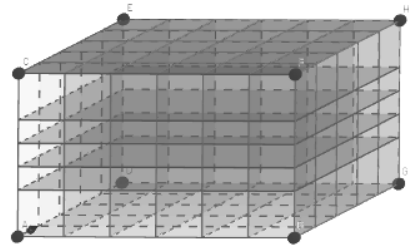

S8A10

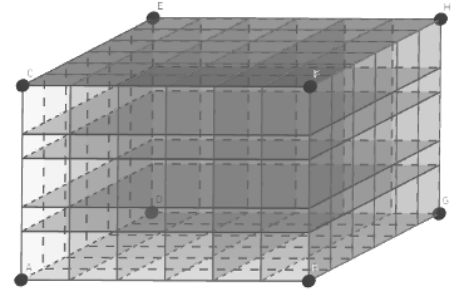

S10A10

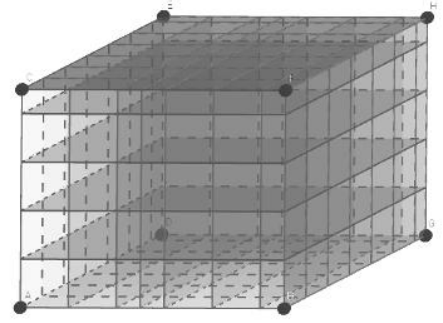

Figura 13 - Conjunto dos gráficos tridimensionais descritivos das soluções analisadas Fonte: Autores (2016)

Da análise do conjunto examinado observa-se que a variabilidade presente nas três dimensões da criatividade é relativamente pequena (os paralelepípedos não revelam contrastes flagrantes embora os seus volumes sejam visivelmente distintos), evidenciando que a variabilidade resulta sobretudo da combinação das três dimensões. Em qualquer dos casos, para o cômputo global da criatividade, ressalta uma forte contribuição do domínio do 
conhecimento matemático (tanto a nível conceptual como a nível processual), assim como da capacidade de lidar com ideias e processos matemáticos por meio de sistemas de representação variados (AIZIKOVITSH-UDI, 2014). Tanto a fluência de conhecimento matemático (não somente conhecimento escolar, mas também conhecimento informal e intuitivo) como a flexibilidade representacional representam acréscimos importantes à magnitude da originalidade nas várias resoluções analisadas. Portanto, a criatividade matemática dos jovens participantes no campeonato espelha não apenas o lado inovador das suas abordagens aos problemas (em termos de estratégias, ideias, conceitos envolvidos), mas também o lado proficiente que se vê na concretização de tais abordagens e na execução de processos matemáticos (HERSHKOVITZ; PELED; LITTLER, 2009; SILVER, 1997).

Nas várias resoluções verifica-se o recurso a diversos conceitos e procedimentos diretamente relacionados com conjuntos e relações de inclusão e interseção, comparação de cardinais de conjuntos, operações e cálculos numéricos, modos de contagem informais, todos eles úteis para lidar com os dados fornecidos no problema e para chegar à solução. A presença da fluência do conhecimento matemático é demonstrada pela capacidade dos solucionadores de fazerem a escolha de estratégias apropriadas para conduzir um raciocínio que permite resolver o problema (NCTM, 2014). Aqui, o raciocínio matemático é entendido como a habilidade demonstrada para compreender a questão levantada no enunciado e para construir abordagens que levam à solução do problema. Trata-se de conseguir relacionar esquemas de raciocínio e métodos de resolução com a compreensão da informação disponibilizada no problema (FREIMAN, 2006).

A flexibilidade representacional, com implicações visíveis na originalidade das resoluções dos alunos, revelou-se nos seus processos de comunicação matemática por meio dos vários tipos de representações a que recorreram (tabelas, esquemas, diagramas de Venn, símbolos, linguagem natural, inscrições, elementos pictóricos, cores...). As representações utilizadas permitiram, desde logo, expor as formas de raciocínio mobilizadas e o modo como os alunos aplicaram o conhecimento matemático necessário para resolver o problema. Sendo assim, e tendo em conta os dados recolhidos, a flexibilidade representacional distingue as resoluções segundo os tipos de abordagens seguidas para obter a solução, evidenciando a escolha das representações mais apropriadas para comunicar e exprimir as estratégias adotadas (STARKO, 2010). Desta forma, confirma-se que embora a originalidade seja uma componente importante da criatividade, não é suficiente para caracterizar todos os aspectos criativos presentes nas resoluções (RUNCO, 2003, 2006; RUNCO; JAEGER, 2012). 
Do mesmo modo, as dimensões da fluência do conhecimento matemático e da flexibilidade representacional, se tomadas isoladamente, não asseguram a manifestação da qualidade criativa dos produtos, tal como sublinham vários autores. Por exemplo, alguns casos indicativos de uma menor fluência de conhecimento matemático, como o da resolução S10A10 (Figura 12), demonstram que o uso de um processo menos sofisticado quanto ao uso de formalizações matemáticas não equivale a uma menor criatividade matemática.

Nessa resolução impera, em contrapartida, uma boa capacidade de usar representações simples, diretas e de natureza eminentemente icônica (círculos coloridos de formas estratégicas) que viabilizam e, ao mesmo tempo, refletem o processo seguido para obter a resposta ao problema. Assim, parece sair reforçada da análise destas resoluções a ideia de que a flexibilidade representacional constitui uma vantagem muito importante para a capacidade de resolução de problemas e tem uma influência clara na criatividade matemática dos produtos criados pelos participantes no SUB12. Em particular, há indícios de que a originalidade das resoluções é diretamente influenciada pela flexibilidade representacional, ou seja, pela capacidade de representar o conhecimento e o pensamento matemático de formas singulares.

A caracterização da criatividade matemática manifestada nas 10 resoluções mostra a fluência do conhecimento matemático como decisiva para a compreensão do problema e para a mobilização de ideias e conceitos relevantes, ao mesmo tempo que o modo original de os representar implica a presença de flexibilidade representacional. Desta forma, o domínio do conhecimento, no campo conceptual do problema, é determinante para relacionar e organizar a informação disponibilizada no enunciado e determina o modo como esta é usada para obter a resposta correta (SHEFFIELD, 2009). Neste contexto, a fluência do conhecimento matemático associa-se ao significado matemático do problema e a flexibilidade representacional está associada ao uso, aplicação e eficácia de ferramentas importantes (mais ou menos informais) para levar a cabo o processo de resolução.

\section{Conclusões}

De acordo com os resultados obtidos mediante a aplicação do referencial de análise, em termos dos indicadores Originalidade, Fluência do Conhecimento Matemático e Flexibilidade Representacional, encontramos alguma variabilidade no agregado das três dimensões postuladas para a criatividade matemática. A interpretação destes resultados leva a considerar que: i) a criatividade matemática manifestada nas resoluções apresenta uma certa 
heterogeneidade, o que parece ser compatível com o contexto de uma competição inclusiva, que abrange uma larga diversidade de crianças participantes (são portanto plausíveis diversos graus de fluência e de flexibilidade representacional em Matemática nos muitos participantes); ii) a heterogeneidade da criatividade das resoluções não decorre de uma grande dispersão nas medidas obtidas em cada uma das dimensões; pelo contrário, há uma reduzida amplitude para cada um dos três indicadores; iii) a criatividade matemática é visivelmente sustentada pela influência combinada das três dimensões (sobressaindo o volume do paralelepípedo como elemento distintivo), não se verificando casos extremos de preponderância ou desaparecimento de uma das três dimensões (isto é, não aparecem paralelepípedos "aplanados"); iv) as evidências obtidas apontam para a caracterização da criatividade matemática das resoluções como uma criatividade que é própria de contextos em que os indivíduos atravessam processos de aprendizagem (BEGHETTO; KAUFMAN, 2007).

A originalidade das resoluções foi tida como um indicador da aptidão para gerar ideias incomuns, que permitem perceber e abordar os problemas de forma diferente, e de uma capacidade de expressão própria para representar o conhecimento mobilizado e assim produzir resoluções únicas (IRISH NATIONAL TEACHERS' ORGANISATION, 2009). Embora seja possível observar alguns pontos comuns entre as resoluções escolhidas, estas foram consideradas resoluções invulgares por revelarem estratégias, abordagens e formas de raciocínio e ainda modos de representação e comunicação distintos dos demais no âmbito do campeonato.

Foi igualmente constatado que o domínio do conhecimento matemático e a sua execução eficiente e perspicaz é importante para a manifestação da criatividade na resolução de problemas. Este resultado é compatível com a ideia defendida por vários teóricos de que os indivíduos que têm um grande domínio do conhecimento matemático têm também maior capacidade para utilizá-lo na criação de conhecimento novo e ser matematicamente criativos (STERNBERG, 2008).

Nas resoluções analisadas, a fluência do conhecimento matemático, traduzida pela ativação, mobilização e aplicação de conceitos e procedimentos potencialmente úteis para lidar com os problemas, bem como a capacidade de expressar claramente o raciocínio matemático, teve reflexos evidentes no nível da criatividade. Na verdade, a criatividade não se pode reduzir à originalidade nem tão pouco à flexibilidade representacional, ainda que estas, sobretudo de forma conjugada, emprestem um grande contributo para a plena amplitude da criatividade. Parece emergir dos dados que, apesar da relevância da originalidade, a robustez da criatividade se torna menor se não houver um certo nível de conhecimento (SRIRAMAN, 
2008) pois o domínio do conhecimento matemático e a capacidade de o representar refletemse na criatividade matemática (RUNCO; JAEGER, 2012; LEIKIN, 2009).

A flexibilidade representacional assume uma natureza bem individualizada e é facilmente apreciável em cada resolução, permitindo exprimir e revelar os raciocínios dos alunos. A flexibilidade reflete a adequação e combinação das representações matemáticas e não matemáticas utilizadas, provenientes de diferentes sistemas de representação conectados (pictórico, simbólico, numérico, textual,...), que permitem relacionar os dados e condições do problema com o conhecimento matemático relevante.

Como resultou da análise, em cada resolução, a combinação de representações para exprimir o pensamento matemático constituiu uma importante evidência de flexibilidade representacional com forte implicação na originalidade dos produtos. Isto permite confirmar que a flexibilidade representacional é importante para caracterizar resoluções de problemas únicas e demonstrativas de grande capacidade imaginativa e inventiva (AINSWORTH, 1999; BENKO; MAHER, 2006). Em geral, constatou-se na análise dos dados que aquilo que é novo, único e diferente, em cada uma das resoluções representadas, não se resume a simples detalhes superficiais, mas reveste-se de sentido matemático e está associado à capacidade de criar, reinventar e combinar formas de representação, isto é, à flexibilidade representacional.

Em síntese, ainda que a originalidade possa ser entendida como a principal componente da criatividade (LEIKIN, 2013), a fluência do conhecimento matemático e a flexibilidade de representação mostraram ter igualmente um papel importante na criatividade matemática. Assim, a criatividade manifestada neste conjunto de resoluções é caracterizada por uma presença das três dimensões, cujo efeito combinado é determinante para a diversidade das resoluções matematicamente criativas, tendo em conta o nível de saber matemático esperado destes alunos.

A liberdade permitida aos participantes, quer no desenvolvimento do raciocínio matemático, quer na comunicação matemática, parece ter influência na promoção de resoluções matemáticas pessoais, inventivas e distintivas. Essa liberdade, que é vincada no contexto do SUB12, trouxe a comunicação do raciocínio para primeiro plano, acentuando a importância da representação de ideias, conceitos e processos matemáticos envolvidos na resolução.

Admite-se, assim, que o contexto competitivo do SUB12 possa ser um fator que estimula a procura de formas eficazes e simultaneamente interessantes de comunicar as resoluções, contribuindo para a riqueza das representações matemáticas e, consequentemente, para o desenvolvimento da criatividade matemática (HEINZE; STAR; VERSCHAFFEL, 
2009). É, com efeito, notória a relação entre o raciocínio matemático e a comunicação matemática nas representações matemáticas dos alunos, bastante individualizadas e imaginativas, tanto as mais informais como as de caráter mais formal. Este fenômeno está em sintonia com as características do Campeonato de Matemática SUB12, por se tratar de um ambiente de resolução de problemas que dá aos participantes oportunidades para usarem os seus próprios processos de resolução, tirando partido do conhecimento matemático que já possuem, bem como da sua experiência concreta, dando-lhes ainda o tempo suficiente que é decisivo para o desenvolvimento da criatividade (POWELL et al., 2009).

\section{Referências}

AINSWORTH, S. The Functions of Multiple Representations. Computers \& Education, Amsterdam, v. 33, n. 2-3, p. 131-152, 1999.

AIZIKOVITSH-UDI, E. The Extent of Mathematical Creativity and Aesthetics in Solving Problems among Students Attending the Mathematically Talented Youth Program. Creative Education, Delaware, v. 5, n. 4, p. 228-241, mar. 2014.

AMARAL, N. A criatividade matemática no contexto de uma competição de resolução de problemas. 2016. 446 f. Tese (Doutorado em Educação, especialidade de Didática da Matemática) Instituto de Educação, Universidade de Lisboa, Lisboa, Portugal, 2016.

APPLEBAUM, M.; SAUL, M. Anecdotes and assertions about creativity in the working mathematics classroom. In: BERMAN, R. A.; KOICHU, B. (Ed.). Creativity in Mathematics and the Education of Gifted Students, Rotterdam, Netherlands: Sense Publishers, 2009. p. 272-284.

BEGHETTO, R. A. Nurturing Creativity in the Micro-Moments of the Classroom. In: KIM, K. H. et al. (Ed.). Creatively gifted students are not like other gifted students: Research, theory, and practice. Rotterdam, Netherlands: Sense Publishers, 2013. p. 3-15.

BEGHETTO, R. A.; KAUFMAN, J. C. Toward a broader conception of creativity: A case for 'mini-c' creativity. Psychology of Aesthetics, Creativity, and the Arts, Washington, DC, v. 1, n. 2, p. 73-79, 2007.

BEGHETTO, R. A.; KAUFMAN J. C. Do we all have multicreative potential? ZDM - International Journal on Mathematics Education, Berlin-Heidelberg, v. 41, n. 1-2, p. 39-44, 2009.

BENKO, P.; MAHER, C. A. Students constructing representations for outcomes of experiments. In: MORAOVÁ, J. N. H.; KRÁTKÁ, M.; STEHLÍKOVÁ, N. (Ed.). In: CONFERENCE OF THE INTERNATIONAL GROUP FOR THE PSYCHOLOGY OF MATHEMATICS EDUCATION, 30., 2006, Prague. Proceedings of the $30^{\text {th }}$ Conference of the International Group for the Psychology of Mathematics Education... Prague, Czech Republic: PME, v. 2, 2006. p. 137-143.

BERTHOLD, K.; RENKL, A. Fostering the Understanding of Multi-Representational Examples by Self-Explanation Prompts. In: BARA, B. G.; BARSALOU, L.; BUCCIARELLI, M. (Ed.). In: ANNUAL COGNITIVE SCIENCE CONFERENCE, 27., 2005, Mahwah. Proceedings of the CogSci... Mahwah, NJ, 2005. p. 250-255. 
BOAVIDA, A. M. et al. A Experiência Matemática no Ensino Básico. 1. ${ }^{a}$ ed. Lisboa: Ministério da Educação, 2008. 133 p.

CANDEIAS, A. A. Criatividade: Perspectiva integrativa sobre o conceito e a sua avaliação. In: MORAIS, M. F.; BAHIA, S. (Org.). Criatividade: Conceito, Necessidades e Intervenção. Braga, Portugal: Psiquilíbrios Edições, 2008. p. 41-63.

CHING, P. An experiment to discover mathematical talent in a primary school in Kampong Air. ZDM - International Journal on Mathematics Education, Berlin-Heidelberg, v. 29, n. 3, p. 94-96, 1997.

CLARY, R. M.; BRZUSZEK, R. F.; FULFORD, C. T. Measuring Creativity: A Case Study Probing Rubric Effectiveness for Evaluation of Project-Based Learning Solutions. Creative Education, Delaware, v. 2, n. 4, p. 333-340, 2011.

FREIMAN, V. Problems to Discover and to Boost Mathematical Talent in Early Grades: A Challenging Situations Approach. The Montana Mathematics Enthusiast, Montana, v. 6, n. 1-2, p. 51-75, 2006.

FREIMAN, V. Mathematical e-nrichement: problem-of-the-week model. In; LEIKIN, R.; BERMAN, A.; KOICHU, B. (Ed.). Creativity in Mathematics and the Education of Gifted Students, Rotterdam: Sense Publishers, 2009. p. 367-381.

FREIMAN, V.; LIRETTE-PITRE, N. Building a virtual learning community of problem solvers: example of CASMI community. ZDM - International Journal on Mathematics Education, BerlinHeidelberg, v. 41, n. 1-2, p. 245-256, 2008.

GUILFORD, J. P. Creativity. American Psychologist, Washington, DC, v. 5, n. 9, p. 444-454, 1950.

HEINZE, A.; STAR, J. R.; VERSCHAFFEL, L. Flexible and adaptive use of strategies and representations in mathematics education. ZDM - International Journal on Mathematics Education, Berlin-Heidelberg, v. 41, n. 5, p. 553-540, 2009.

HERSHKOVITZ, S.; PELED, I.; LITTLER, G. Mathematical creativity and giftedness in elementary school: task and teacher promoting creativity for all. In: LEIKIN, R.; BERMAN, A.; KOICHU, B. (Ed.). Creativity in Mathematics and the Education of Gifted Students. Rotterdam: Sense Publishers, 2009. p. 255-269.

IRISH NATIONAL TEACHERS' ORGANISATION. Creativity and the Arts in the Primary School - Discussion Document and Proceedings of the Consultative Conference on Education 2009. Dublin: Irish National Teachers' Organization, 2009.

KARKOCKIENE, D. Creativity: Can it be Trained? A Scientific Educology of Creativity. cdInternational Journal of Educology, (Lithuanian, Special Issue), Sydney, p. 51-58, 2005. Disponível em: <http://eric.ed.gov/?id=ED494897>. Acesso em: 15 dez. 2015.

KENDEROV, P. S. Competitions and Mathematics Education. In: SANZ-SOLÉ, M. et al. (Ed.). In: INTERNACIONAL CONGRESS OF MATHEMATICIANS, 25., 2006, Madrid. Proceedings of the International Congress of Mathematicians... Madrid: European Mathematical Society, v. 3, 2006. p. 1584-1598.

KENDEROV, P. et al. Challenges Beyond the Classroom: Sources and Organizational Issues. In: BARBEAU, E. J.; TAYLOR, P. J. (Ed.). Challenging Mathematics in and Beyond the Classroom. 1. ${ }^{\text {e }}$ ed. New York: Springer, 2009. p. 53-96. 
KOICHU, B.; ANDZANS, A. Mathematical creativity and giftedness in out-of-school activities. In: LEIKIN, R.; BERMAN, A.; KOICHU, B. (Ed.). Creativity in Mathematics and the Education of Gifted Students. Rotterdam: Sense Publishers, 2009. p. 286-307.

LASSIG, C. J. Creating creative classrooms. The Australian Educational Leader, New South Wales, v. 34, n. 2, p. 8-13, 2012.

LEIKIN, R. Exploring mathematical creativity using multiple solution tasks. In: LEIKIN, R.; BERMAN, A.; KOICHU, B. (Ed.). Creativity in Mathematics and the Education of Gifted Students, Rotterdam: Sense Publishers, 2009. p. 130-144.

LEIKIN, R. Evaluating mathematical creativity: The interplay between multiplicity and insight. Psychological Test and Assessment Modeling, Lengerich, Germany, v. 55, n. 4, p. 385-400, 2013.

LEIKIN, R.; BERMAN, A.; KOICHU, B. Introduction. In: LEIKIN, R.; BERMAN, A.; KOICHU, B. (Ed.). Creativity in Mathematics and the Education of Gifted Students. Rotterdam: Sense Publishers, 2009. p. vii-viii.

MANN, E. L. Mathematical Creativity and School Mathematics: Indicators of Mathematical Creativity in Middle School. 2005. 240 f. Tese (Doutorado em Psicologia Educacional) - University of Connecticut, Storrs, CT, USA, 2005.

MANN, E. L. Creativity: The Essence of Mathematics. Journal for the Education of the Gifted, Waco, Texas, v. 30, n. 2, p. 236-260, 2006.

MAYER, R. E. The Role of Domain Knowledge in Creative Problem Solving. In: KAUFMAN, J. C.; BAER, J. (Ed.). Creativity and Reason in Cognitive Development, New Jersey: Cambridge, 2006. p. $145-158$.

MORAIS, M. F.; AZEVEDO, I. Avaliação da Criatividade como um Contexto Delicado: Revisão de Metodologias e Problemáticas. Avaliação Psicológica, Porto Alegre, v. 8, n. 1, p. 1-15, abr. 2009. Disponível em: <http://pepsic.bvsalud.org/scielo.php?script=sci_arttext\&pid=S1677-

04712009000100002\&lng=pt\&nrm=iso>. Acesso em: 2 jul. 2015.

NCTM. Procedural Fluency in Mathematics: A Position of the National Council of Teachers of Mathematics. Reston: NCTM, 2014. Disponível em: <http://www.nctm.org/about/content.asp $\mathrm{x}$ ?id=42833>. Acesso em: 10 jan. 2015.

NISTAL, A. A. et al. Conceptualising, investigating and stimulating representational flexibility in mathematical problem solving and learning: a critical review. ZDM - International Journal on Mathematics Education, Berlin-Heidelberg, v. 41, n. 3, p. 627-636, 2009.

OLIVEIRA, E. et al. Análise de Conteúdo e Pesquisa na Área da Educação. Revista Diálogo Educacional, Curitiba, v. 4, n. 9, p. 11-27, maio/ago. 2003.

OREY, D. C. Manifestations of mathematical inventiveness in at-risk (Immigrant) high school students performing arithmetical calculations. In: BROSNAN, P.; ERCHICK, D. B.; FLEVARES, L. (Ed.). ANNUAL MEETING OF THE NORTH AMERICAN CHAPTER OF THE INTERNATIONAL GROUP FOR THE PSYCHOLOGY OF MATHEMATICS EDUCATION, 32 ., 2010, Ohio. Proceedings... Ohio, USA: PME, v. 4, 2010. p. 327-333.

POWELL, A. B. et al. Challenging Tasks and Mathematics learning. In: BARBEAU, E. J.; TAYLOR, P. J. (Ed.). Challenging Mathematics in and Beyond the Classroom. 1. a ed. New York: Springer, 2009. p. 133-169. 
RUNCO, M. A. Education for Creative Potential. Scandinavian Journal of Educational Research, New York, v. 47, n. 3, p. 319-324, 2003.

RUNCO, M. A. Reasoning and Personal Creativity. In: KAUFMAN, J. C.; BAER, J. (Ed.). Creativity and Reason in Cognitive Development. New Jersey: Cambridge, 2006. p. 99-116.

RUNCO, M. A.; JAEGER, G. J. The Standard Definition of Creativity. Creativity Research Journal, New York, v. 24, n. 1, p. 92-96, 2012.

RUSSEL, S. J. Principles and Standards: Developing Computational Fluency with Whole Numbers. Teaching Children Mathematics, Reston, VA, v. 7, n. 3, p. 154-158, 2000.

SHARMA, K.; TEPER, Y. The Gifted and Talented: Creativity, Cultural Perspectives and Skills. In: LEIKIN, R. (Ed.). In: INTERNATIONAL CONFERENCE ON CREATIVITY IN MATHEMATICS AND THE EDUCATION OF GIFTED STUDENTS, 5., 2008, Haifa. Proceedings... Haifa, Israel: MCG - International Group for Mathematical Creativity and Giftedness, 2008. p. 211- 215.

SHEFFIELD, L. J. Developing mathematical creativity - Questions may be the answer. In: LEIKIN, R.; BERMAN, A.; KOICHU, B. (Ed.). Creativity in Mathematics and the Education of Gifted Students. Rotterdam: Sense, 2009. p. 88-100.

SILVER, E. A. Fostering Creativity through Instruction Rich in Mathematical Problem Solving and Problem Posing. ZDM - International Journal on Mathematics Education, Berlin-Heidelberg, v. 29, n. 3, p. 75-80, 1997.

SRIRAMAN, B. Are Mathematical Giftedness and Mathematical Creativity Synonyms? A Theoretical Analysis of Constructs. In: SRIRAMAN, B. (Ed.). Creativity, Giftedness, and Talent Development in Mathematics. Charlotte, USA: IAP, 2008. p. 85-112.

STARKO, A. J. Creativity in the Classroom: Schools of Curious Delight. 4. ${ }^{a}$ ed. New York: Routledge, 2010. 356 p.

STEINBERG, R. A Mathematically Creative Four-Year-Old - What Do We Learn from Him? Creative Education, Delaware, v. 4, n. 7A, p. 23-32, 2013.

STERNBERG, R. J. Teaching for Creativity. In: YAMIN, T. S. (Ed.). Excellence in Education 2008: Future Minds and Creativity. Paris, France: The International Centre for Innovation in Education, 2008. p. 55-70.

TAYLOR, P.; GOURDEAU, F.; KENDEROV, P. The role of mathematical competitions in mathematics education. In: NISS, M. (Ed.). In: INTERNATIONAL CONGRESS ON MATHEMATICAL EDUCATIONON, 10., 2004, Roskilde. Proceedings of the 10th International Congress on Mathematical Education. Roskilde, Denmark: Roskilde University, 2004. p. 495-497.

Submetido em 19 de Junho de 2016. Aprovado em 16 de Abril de 2017. 